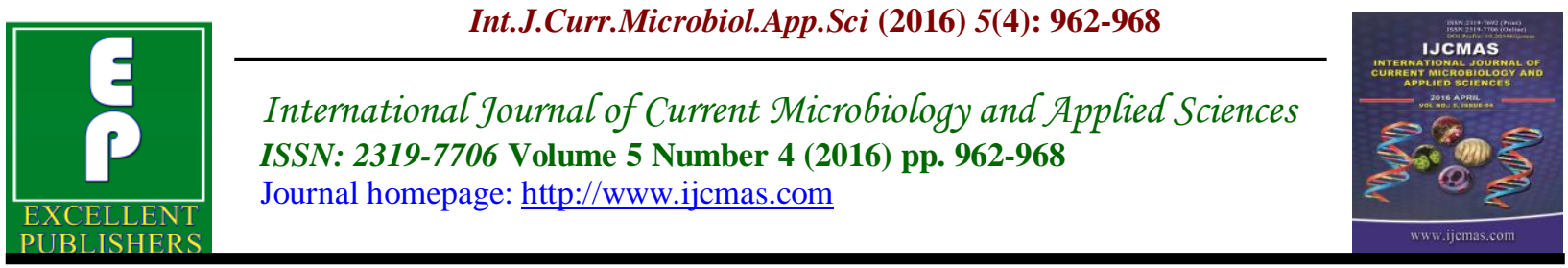

Original Research Article

http://dx.doi.org/10.20546/ijcmas.2016.504.109

\title{
Prevalence and Antimicrobial Susceptibility Pattern of Proteus Species in Clinical Samples
}

\author{
Rajiv Ranjan Prasad ${ }^{1 *}$, Vijay Shree ${ }^{2}$, Satyendu Sagar ${ }^{1}$, Sunil Kumar $^{4}$ and Prabhat Kumar ${ }^{1}$ \\ ${ }^{1}$ Department of Microbiology, NMCH, Patna, India \\ ${ }^{2}$ Department of Community Medicine, IGIMS, Patna, India \\ *Corresponding author
}

\begin{abstract}
A B S T R A C T
Keywords

Antibiotic

susceptibility

pattern,

Proteus,

UTI,

Cefotaxim

\section{Article Info}

Accepted:

25 March 2016

Available Online:

10 April 2016

Different Proteus species may vary with the type of infections they cause in both the community and hospital environments. However, in many laboratories in developing countries, differentiation of the genus Proteus into species is not generally done during bacteriological diagnosis due to high cost and special skills involved. This study aimed at determining the prevalence of different Proteus species in Nalanda Medical College and Hospital, PATNA, their antibiotic resistance pattern and how they relate to patients' demographic data. This is a prospective study involving the analyses of clinical samples for Proteus species and determining their antimicrobial susceptibility pattern. Thirty two Proteus species were isolated from 1910 clinical specimens obtained from patients suspected of bacterial infection, giving $1.67 \%$ prevalence of Proteus infections. Wound isolates were the highest followed by urine. Three Proteus species; $P$. mirabilis, $P$. vulgaris and $P$. penneri were recovered from the samples. P. mirabilis was the commonest species $(59.38 \%)$, and hence the causative species of a majority of Proteus infections followed by P. vulgaris $(34.37 \%)$, and P. penneri (6.25\%). The three Proteus species recovered were highly resistant to ampicillin, cefuroxime, netillin and pefloxacin. This study has also provided information for use in generating national data.
\end{abstract}

\section{Introduction}

Proteus is a genus of Gram-negative bacteria belonging to the family of Enterobactericeae. Proteus species are distinguishable from most other genera by their ability to swarm across an agar surface (Jacobsen et al., 2008). Proteus is widespread in the environment and makes up part of the normal flora of the human gastrointestinal tract. Proteus ranks third as the cause of hospital-acquired infections (Stamm, 1999). Three species: P.vulgaris, $P$. mirabilis, and $P$. penneri are opportunistic human pathogens (Guentzel, 1996).
Proteus species are the major cause of diseases acquired outside the hospital, where many of these diseases eventually require hospitalization (De Champs et al., 2000). Proteus species, particularly P. Mirabilis, is believed to be the most common cause of infection-related kidney stone, one of the most serious complications of unresolved or recurrent bacteruria (Coker et al., 2000). $P$. mirabilis has been implicated in meningitis, empyema, osteomyelitis and gastroenteritis. Also, it frequently causes nosocomial infections of the urinary tract (46\%), 
surgical wounds (24\%) and lower respiratory tract $(30 \%)$. Less frequently, proteus species cause bacteraemia (17\%), most often in elderly patients (Mansy, 2001). The phenomenal evolution and increase of multidrug-resistance of many bacterial pathogens is increasing and representing a growing public health problem in the world. Evolution and spread of a multidrug-resistant Proteus mirabilis clone with chromosomal AmpC-type betalactamase was reported in Europe (Luzzaro et al., 2009; D'Andrea et al., 2011).

Multidrug-resistance of Proteus spp. calls for regular review of antimicrobial sensitivity pattern among clinically isolated Proteus spp. in order to be able to decide which antibiotic to be prescribed.

\section{Materials and Methods}

\section{Specimens' Collection}

Different clinical samples such as sputum, wound swab, cerebrospinal fluid (CSF), tracheal aspirate (Tr. asp.), throat aspirate, pus, abdominal abscess ear swab, bed sores, peritoneal wound swab, pleural fluid were collected from 1910 patients (Inpatient and Outpatient) of Nalanda Medical College and Hospital, Patna, Bihar, India. Demographic data such as sex of the patients was recorded prior to sample collection.

\section{Cultivation and Identification}

The clinical samples collected were aseptically inoculated on plates of Blood agar, Chocolate agar Cystine-LactoseElectrolyte-Deficient (CLED) agar and MacConkey agar (Oxoid Cambridge, UK) and incubated at $37^{\circ} \mathrm{C}$ for $24 \mathrm{~h}$. The morphological characteristics of the colonies including size, shape, colour, pigmentation and haemolytic nature were recorded. Suspected Proteus colonies were isolated and identified through biochemical tests according to Barrow and Felthan:[9] based on whether they were positive for nitrate reduction; $\mathrm{H} 2 \mathrm{~S}$ gas production; methyl-red and urease reactions; and negative for lactose fermentation.

\section{Antimicrobial Susceptibility Test}

Modified Kirby-Bauer disk diffusion method (Cheesebrough, 2000) was used to test the susceptibility of the Proteus isolates to different antimicrobial agents(obtained from BDH London, UK): ampicillin $(10 \mu \mathrm{g})$, tetracycline $(30 \mu \mathrm{g})$, chloramphenicol(30 $\mu \mathrm{g})$, cefuroxime $(30 \mu \mathrm{g})$, ceftriaxone $(30 \mu \mathrm{g})$, cefotaxime $(30 \mu \mathrm{g})$, gentamicin $(10 \mu \mathrm{g})$, amikacin $(10 \mu \mathrm{g})$ and co-trimoxazole $(25$ $\mu \mathrm{g})$. The inocula were prepared by growing the various Proteus species on separate agar plates and colonies from the plate were transferred with inoculating loop into $3 \mathrm{ml}$ of normal saline in a test tube. The density of these suspensions was adjusted to 0.5 McFarland standards. The surface of MullerHinton agar (Oxoid Cambridge, UK) plate was evenly inoculated with the organisms using a sterile swab. The swab was dipped into the suspension and pressed against the side of the test tube to remove excess fluid. The wet swab was then used to inoculate the Muller-Hinton agar by evenly streaking across the surface. By means of Disc Dispenser (Oxoid Cambridge, UK), the antibiotic discs were applied to the surface of the inoculated agar and the plates were incubated overnight at $37^{\circ} \mathrm{C}$. The diameter of zone of growth-inhibition observed was measured and compared to the chart provided by National Committee for Clinical Laboratory Standards (NCCLS).

\section{Results and Discussion}

Three Proteus species were recovered from 32 of the 1910 clinical samples collected (Table 1) and this gave a prevalence rate of 
$1.67 \% .23$ of these samples $(71.87 \%)$ were taken from male patients and $9(28.13 \%)$ from females. All the age groups except 9099 years age group had at least one species present. P. mirabilis being the highest with $59.38 \%$ (Figure 1) that could be detected among all the age groups (Table 2) except $<1$ years old and 90-99years old age groups. P. vulgaris accounted for $34.37 \%$ of the Proteus isolates and was present in all the age groups except 1-9 years, 80-89 years and 90 - 99 years age group. P. penneri $(6.25$ $\%)$ was absent in samples obtained from < 1years, 1-9 years, 10-19 years, 30-39 years, 50 - 59 and 90 - 99 years age groups. Wound samples contributed the highest percentage of Proteus followed by urine.

\section{Antimicrobial Susceptibility of the Proteus Isolates}

The Proteus isolates recovered were highly susceptible to Cefotaxime, Ofloxacin, Gentamycin, Amikacin, Lomefloxacin, Ciprofloxacin and Cefaperazone. However, $53.12 \%$ of Proteus isolates exhibited resistance to ampicillin, $28.12 \%$ to Netilline and $18.76 \%$ each Cefuroxime and Pefloxacin(Figure -2) Species identification and surveillance ofantimicrobial resistance is essential in management and control of infections. These practices are usually absent in most of our hospitals mainly due to the high costs involved. Three Proteus species ( $P$. mirabilis, $P$. vulgaris and $P$. penneri) were identified to be responsible for causing infections in various anatomical sites. $P$. mirabilis was the most common species isolated, accounting for $59.38 \%$ of all the infections and hence responsible for the majority of Proteus infections. This result agrees with similar studies conducted in England, Wales and Northern Ireland [Chow, 1979; Jones, 2003].

Table.1 Distribution of Proteus Species among In-patient and Out-patient in Relation to Specimen Type

\begin{tabular}{|c|c|c|c|c|c|}
\hline Samples & Proteus species & In- patients & Out-patients & $\begin{array}{l}\text { Total no. of } \\
\text { Species }\end{array}$ & $\begin{array}{l}\text { Total no. of } \\
\text { Isolates }\end{array}$ \\
\hline \multirow[t]{3}{*}{ Pus } & $\mathrm{Pm}$ & 9 & 3 & 12 & \multirow[t]{3}{*}{19} \\
\hline & $\mathrm{Pv}$ & 4 & 2 & 6 & \\
\hline & $\mathrm{Pp}$ & 0 & 1 & 1 & \\
\hline \multirow[t]{3}{*}{ Urine } & Pm & 2 & 1 & 3 & \multirow[t]{3}{*}{8} \\
\hline & $\mathrm{Pv}$ & 3 & 1 & 4 & \\
\hline & $\mathrm{Pp}$ & 0 & 1 & 1 & \\
\hline \multirow[t]{3}{*}{ Sputum } & $\mathrm{Pm}$ & 0 & 1 & 1 & \multirow[t]{3}{*}{1} \\
\hline & $\mathrm{Pv}$ & 0 & 0 & 0 & \\
\hline & $\mathrm{Pp}$ & 0 & 0 & 0 & \\
\hline \multirow[t]{3}{*}{ Ear swab } & $\mathrm{Pm}$ & 1 & 1 & 2 & \multirow[t]{3}{*}{2} \\
\hline & $\mathrm{Pv}$ & 0 & 0 & 0 & \\
\hline & $\mathrm{Pp}$ & 0 & 0 & 0 & \\
\hline \multirow[t]{4}{*}{ Blood } & $\mathrm{Pm}$ & 0 & 1 & 1 & \multirow[t]{3}{*}{2} \\
\hline & $\mathrm{Pv}$ & 1 & 0 & 1 & \\
\hline & $\mathrm{Pp}$ & 0 & 0 & 0 & \\
\hline & & $20 / 32(62.50 \%)$ & $12 / 32(37.50 \%)$ & & 32 \\
\hline
\end{tabular}


Fig.1 Species Distribution

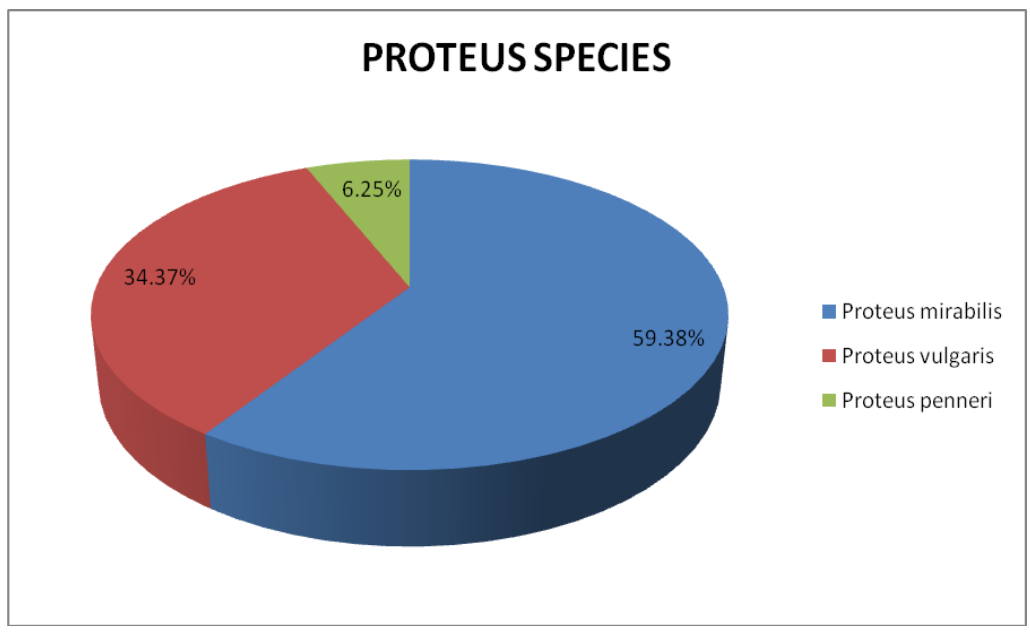

Fig.2 Showing Antibiotic Sensitivity Pattern of Proteus Mirabilis

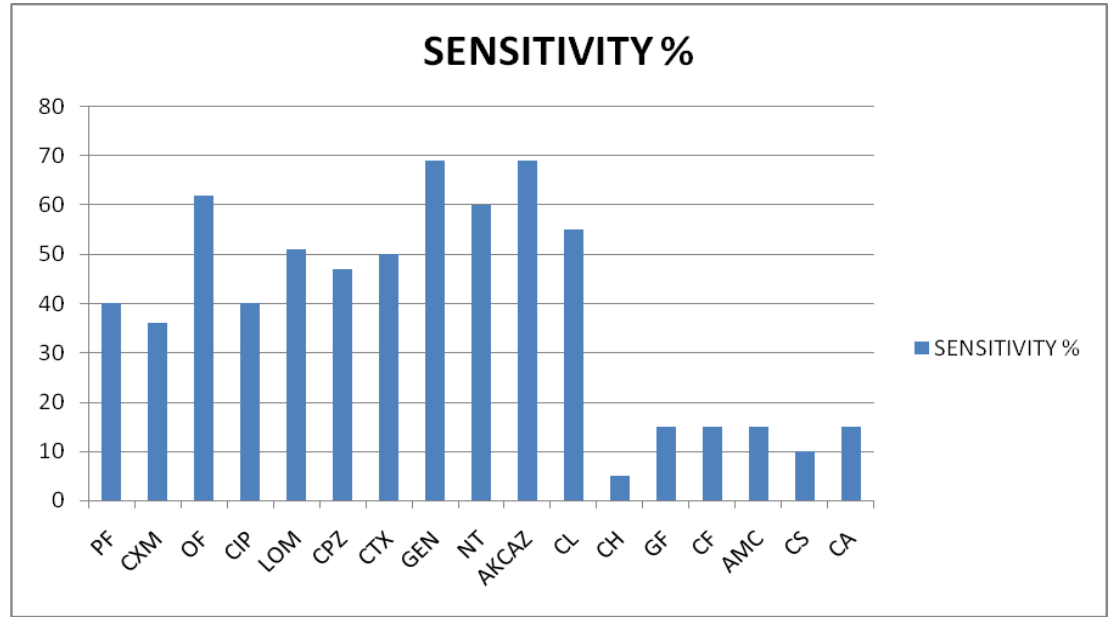

Wounds recorded the highest percentage of Proteus isolates $(67.85 \%)$ followed by urine (19.64\%). Our findings thus partially supports the findings of those from Europe and Asia; [Reslinski, 2005; Chung, 1999] which showed Proteus species to be more commonly encountered in urine than in other clinical specimens. P. mirabilis has a higher propensity for colonizing the urinary tract due to difference in its pathogenicity (Mobley, 1994). Proteus infections were also common among the in-patients $(62.50$ $\%)$ as compared to out-patients $(37.50 \%)$. Out of the 32 clinical specimens from which Proteus was recovered, 23 (71.87\%) were collected from males and $9(28.13 \%)$ from females. The study showed a significant difference between the males and females infected with Proteus. The Proteus infections were detected in all age groups from <1 to 99 years where 60-69 years age group registering as the highest group infected $(23.21 \%)$. The Proteus species isolated were found to have high antimicrobial resistance against third generation of Cephalosporin antibiotics. All the Proteus species were highly sensitivite to Cefotaxime, Ciprofloxacin, Lomefloxacin, Cefoperazone, Cefuroxime, Ofloxacin, Ceftazidime, Gentamycin, 
Netilline and Amikacin.

In conclusion, the high antibiotic resistance of Proteus may be an indication of the resistance levels among the enterobacteriaceae and perhaps salmonellae since indiscriminate ingestion of antibiotics provides selective pressure, leading to a higher prevalence of resistant bacteria (Levy, 1999) which is very common in developing countries likeIndia. Not only are these species potential causes of infections but also potential reservoirs of resistance genes that could be transferred to other bacterial pathogens.

P. mirabilis, $P$. vulgaris and $P$. penneri are the species implicated in Proteus infections; wounds recorded the highest incidence of Proteus infection at NMCH Patna,Bihar. The species were susceptible to Cefotaxime, Ofloxacin, Gentamycin, Amikacin, Lomefloxacin, Ciprofloxacin and Cefaperazone. They were, however resistant to ampicillin, Netilline and Cefuroxime and Pefloxacin and hence these must not form part of the empirical antibiotics for the treatment of Proteus infections at $\mathrm{NMCH}$ Hospital.

\section{Acknowledgement}

The authors would like to thank the personnel of Laboratory and Faculty of Microbiology, Nalanda Medical College and Hospital,Patna for their cooperation.

\section{References}

Barrow G.I. and R.K.A. Felthan (2003) Cowan and Steel's Manual for the Identification of Medical Bacteria. 3rd Ed. Cambridge University Press. Cambridge UK. 351-353.

Biedenbach, D. J., and R. N. Jones. (1994). Predictive accuracy of disk diffusion test for Proteus vulgaris and Providencia species against five newer orally administered cephalosporins, cefdinir, cefetamet, cefprozil, cefuroxime, and loracarbef. J. Clin. Microbiol. 32:559-562.

Burke, J. P., D. Ingall, J. O. Klein, H. M. Gezon, and M. Finland. (1971). Proteus mirabilis infections in a hospital nursery traced to a human carrier. N. Engl. J. Med. 284:115121.

Charles Bryan. infectious disease, chapter seven, urinary tract infections. copyright (2011), The Board of Trustees of the University of South Carolina.

Chow A.W., Taylor P.R., Yoshikawa T.T., and L.B. Guze (1979). A nosocomial outbreak of infection due to multiple strains of resistant Proteus mirabilis: Role of intestinal colonization as a major reservoir. J. Infect. Dis. 139:621-627.

Crett (1999) Prevalence of Proteus species in urinary tract infections in a regional hospital in Trinidad. Zhonghua Yi Xue Za Zhi (Taipei), 62:438-442.

Coker, C.; Bakare, O.O. and H.L.T. Mobley (2000): H-NS Is a repressor of the Pr. mirabilis urease transcriptional activator gene ure R. J. Bacteriol. 128 (9): 2649-2553.

Dance, D. A. B., A. D. Pearson, D. V. Seal, and J. A. Lowes. (1987). A hospital outbreak caused by a chlorhexidineand antibiotic-resistant Proteus mirabilis. J. Hosp. Infect. 10:10-16.

D'Andrea M.M., Literacka E., Zioga A., Giani T., Baraniak A., Fiett J.,Sadowy E., Tassios P.T., Rossolini G.M., Gniadkowski M., and V. De Champs, C., Bonnet, R., Sirot, D., Chanal, C. and J. Sirot (2000). 
Clinical relevance of $P r$. mirabilis in hospital patients: A two year survey. J Antimicrob. Chemoth. 45: 537-539

El-Tahawy A.T (2000). Bacteriology of diabetic foot infections. Saudi Medical Journal; 21 (4): 344-347

Fass, R. J., J. Barnishan, and L. W. Ayers. (1995). Emergence of bacterial resistance to imipenem and ciprofloxacin in a university hospital. J. Antimicrob. Chemother. 36:343353.

Feglo P.K., Gbedema S.Y., Quay S.N.A., Adu-Sarkodie Y., and C. Opokuokrah (2010). Occurrence, species distribution and antibiotic resistance of Proteus isolates: A case study at the Komfo Anokye Teaching Hospital (KATH) in Ghana. International Journal of Pharma Sciences and Research (IJPSR), 1(9): 347-352.

Fuchs, P. C., A. L. Barry, S. D. Brown, and the AST Surveillance Group. (1996). Survey of antimicrobial activity of four commonly used third generation cephalosporins tested against recent bacterial isolates from ten American medical centers, and assessment of disk diffusion test performance. Diagn. Microbiol. Infect. Dis. 24:213-219.

Guentzel M.N. (1996). Escherichia, Klebsiella, Enterobacter, Serratia, Citrobacter, and Proteus. In: Barron's Medical Microbiology (Barron 's et al., eds.) (4th ed.). Univ of Texas Medical Branch.

Jones R., Vincent B.A., and W.B. Saunders (2003). Bacteraemia, England, Wales and Northern Ireland: Commun Dis Rep CDR.

Wkly K. Larry Smith and J.S. Hogan. (2008). Environmental Mastitis: Know Your Opponent. NMC Regional Meeting Proceedings.
Levy. S.B., 1999. Antibiotic resistance: an ecological inbalance. Ciba Found. Symp. 207:1-14.

Luzzaro F., Brigante G., D'Andrea M.M., Pini B., Giani T., Mantengoli E., Rossolini G.M., Toniolo A. (2009). Spread of multidrug-resistant Proteus mirabilis isolates producing an AmpC-type beta-lactamase: epidemiology and clinical management. Int. J. Antimicrob. Agents. 33(4):328-33.

Makled A. and A. Alghamdi. (2006). Surveillance of Aminoglycosides Resistance Among Proteus mirabilis Isolates From Different Units in Jeddah Hospitals, Saudi Arabia. Egypt. J. Med. Microbiol., 15 (2), 33 7-351.

Mansy, M.S.M. (2001): Genomic fingerprinting using random amplified polymorphic DNA for discrimination between $P r$. mirabilis strains. Egypt. J. Biotech. (9):67-79.

Mobley, H.L.T., 1994. Virulence of Proteus mirabilis in urinary tract infections. Molecular pathogenesis and clinical management. ASM Press, Washington, D.C. 245269.

Nawal, V.I., et al. 1994. In vitro antimicrobial activities against Proteus species isolated from patients in a Tertiary care Hospital in Jordan: Frequency of isolation and Epidemiology scienti. Res. Essay. 3(4);122-126

Newman M.J., Frimpong E., Asamoah-Adu A., and E. Sampane-Donkor (2006) Resistance to Antimicrbial Drugs in Ghana. The Ghanaian-Dutch collaboration for Health Research and Development, 1-6.

O'Hara C.M., Brenner F.W., and J.M. Miller. (2000). Classification, Identification, and Clinical Significance of Proteus, 
Providencia, and Morganella. Clinical Microbiology Reviews, 13 (4): 534-546.

Oqunshe, A. A. O. (2006): In vitro phenotypic antibiotic resistance in bacterial flora of some indigenous consumed herbal medications in Nigeria. J. Ru. and Tr. Pub. Health. 5: 9-15.

Reslinski A, Gospodarek E, Mikucha A. (2005) Prevalence of multi-drug resistant Proteus species in clinical specimens and their susceptibility to antibiotics, Med. Dosw. Micribial, 57(2): 175-184.

Ronald, A. R. (1994). Urethritis and cystitis, p. 564-570. In P. D. Hoeprich, M. C. Jordan, and A. R. Ronald (ed.), Infectious disease: a treatise of infectious processes, 5th ed. J. Lippincott, Philadelphia, Pa.

Jacobsen, S. M., Stickler, D. J. Mobley, H. L. T. and M. E. Shirtliff (2008). Complicated Catheter-Associated Urinary Tract Infections Due to Escherichia coli and Proteus mirabilis. Clinical Microbiology Reviews, 21 (1): 26-59.

Sekowska A., Janicka G., Wróblewska J., and E. Kruszyńska (2004). Prevalence of Proteus mirabilis strains in clinical specimens and evaluation of their resistance to selected antibiotics. Pol Merkur Lekarski.17(101):538-40.

Stamm, W.E. (1999): Urinary Tract Infections. In Clinical Infectious Disease: A practical approach, Root,
K. (ed). P: 649-656. Oxford University Press, Inc, New York.

Swenson, J. M., J. A. Hindler, and L. R. Peterson. (1999). Special phenotypic methods for detecting antibacterial resistance, p. 1563-1577. In P. R. Murray et al. (ed.), Manual of clinical microbiology, 7th ed. American Society for Microbiology, Washington, D.C.

Thomson, K. S., W. E. Sanders, and C. C. Sanders. (1994). USA resistance patterns among UTI pathogens. J. Antimicrob. Chemother. 33(Suppl. A): 9-15.

Thornsberry, C., and C. Yee. (1996). Comparative activity of eight antimicrobial agents against clinical bacterial isolates from the United States, measured by two methods. Am. J. Med. 100 (Suppl. 6A):26S$38 \mathrm{~S}$.

Yah S.C., Egbanfona N.O., Oranusi S., and A.M. Abouo (2001) Widespread plasmid resistance genes among Proteus species in diabetic wounds of patients in Ahmadu Bello University Teaching Hospital (ABUTH) Zaria, Afr. J. Biotechnol. 6(15):1757-1762.

Yao, J. D. C., and R. C. Moellering, Jr. (1999). Antibacterial agents, p. 1474-1504. In P. R. Murray et al. (ed.), Manual of clinical microbiology, $7^{\text {th }}$ Ed. American Society of Microbiology, Washington, D.C.

\section{How to cite this article:}

Rajiv Ranjan Prasad, Vijay Shree, Satyendu Sagar, Sunil Kumar and Prabhat Kumar. 2016. Prevalence and Antimicrobial Susceptibility Pattern of Proteus Species in Clinical Samples. Int.J.Curr.Microbiol.App.Sci.5(4): 962-968. doi: http://dx.doi.org/10.20546/ijcmas.2016.504.109 